Supporting Information for:

\title{
Validation and mechanism of a low-cost graphite carbon electrode for electrochemical brine valorization
}

\author{
Linchao Mu, Yichong Wang, William A. Tarpeh*
}

Department of Chemical Engineering, Stanford University, Stanford, CA, 94305, USA

Linchao Mu, Email: linchao@stanford.edu. Address: 443 Via Ortega, Room SB23, Stanford CA, 94305. Telephone: 650-497-1324

Yichong Wang, Email: yichong-16@mails.tsinghua.edu.cn. Address: 443 Via Ortega, Room SB23, Stanford CA, 94305. Telephone: 650-497-1324

*Corresponding author, William A. Tarpeh, Email: wtarpeh@stanford.edu. Address: 443 Via Ortega, Room 387, Stanford CA, 94305. Telephone: 650-497-1324

$$
\begin{gathered}
6 \text { pages } \\
2 \text { tables } \\
9 \text { figures }
\end{gathered}
$$



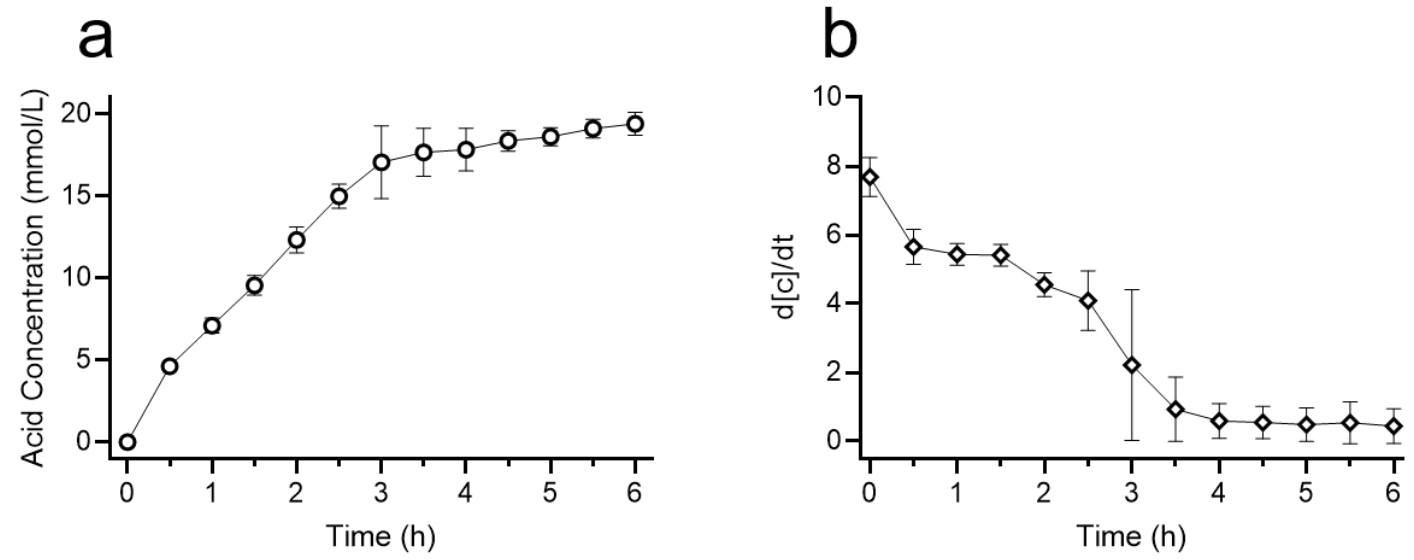

Figure S1. (a) Acid generation during brine splitting over time. Based on nearly plateauing after 3 $\mathrm{h}$, we ran experiments for $3 \mathrm{~h}$. (b) The derivative of the curve in (a) for further indication that the rate of change of acid concentration approached zero at times greater than $3 \mathrm{~h}$. Error bars are \pm one standard deviation for triplicate experiments, and are not shown if smaller than symbols. Anode: Ti-Ir. Cathode: stainless steel. Feeding chloride concentration: 11,000 ppm. Buffer: $0.1 \mathrm{M} \mathrm{Na}_{2} \mathrm{CO}_{3} /$ $0.1 \mathrm{M} \mathrm{NaHCO}_{3}$.

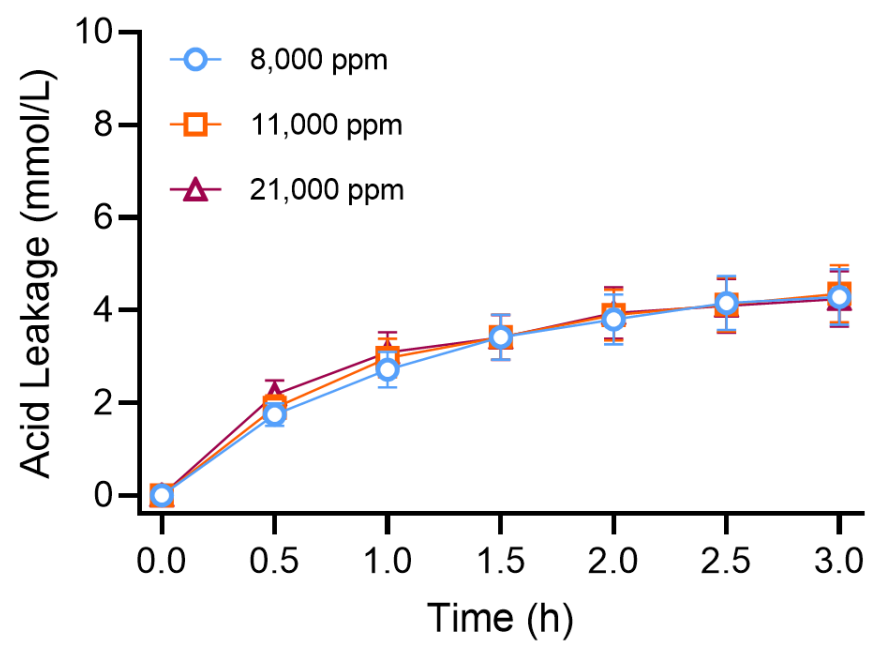

Figure S2. Acid leakage with different feed concentrations, calculated by subtracting the measured proton from the theoretical acid generation. 


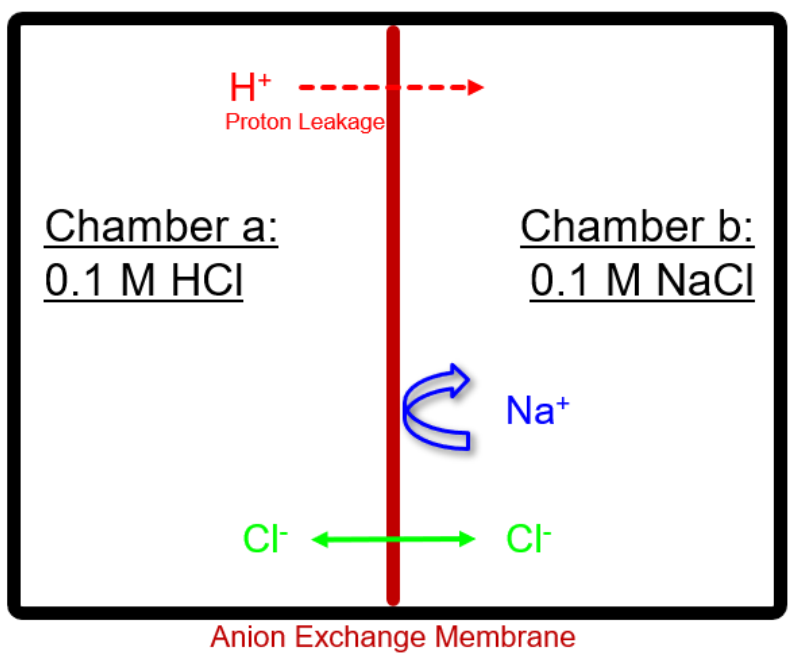

b

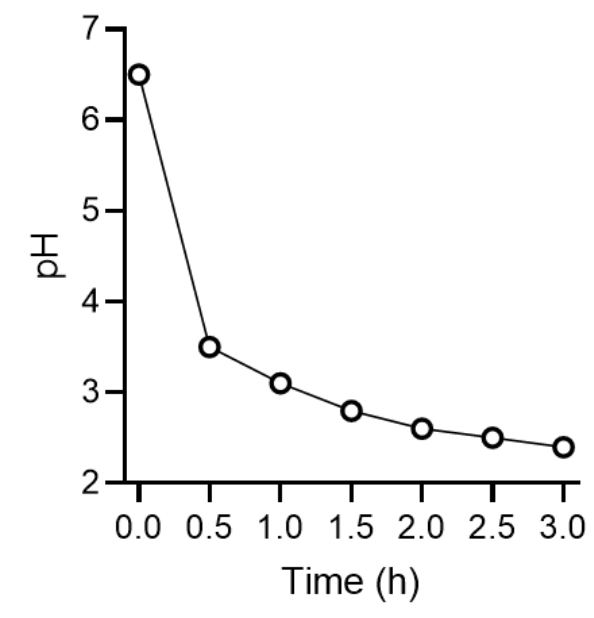

Figure S3. (a) Schematic description of ion migration for AEM without bias. (b) $\mathrm{pH}$ detected in the right chamber.
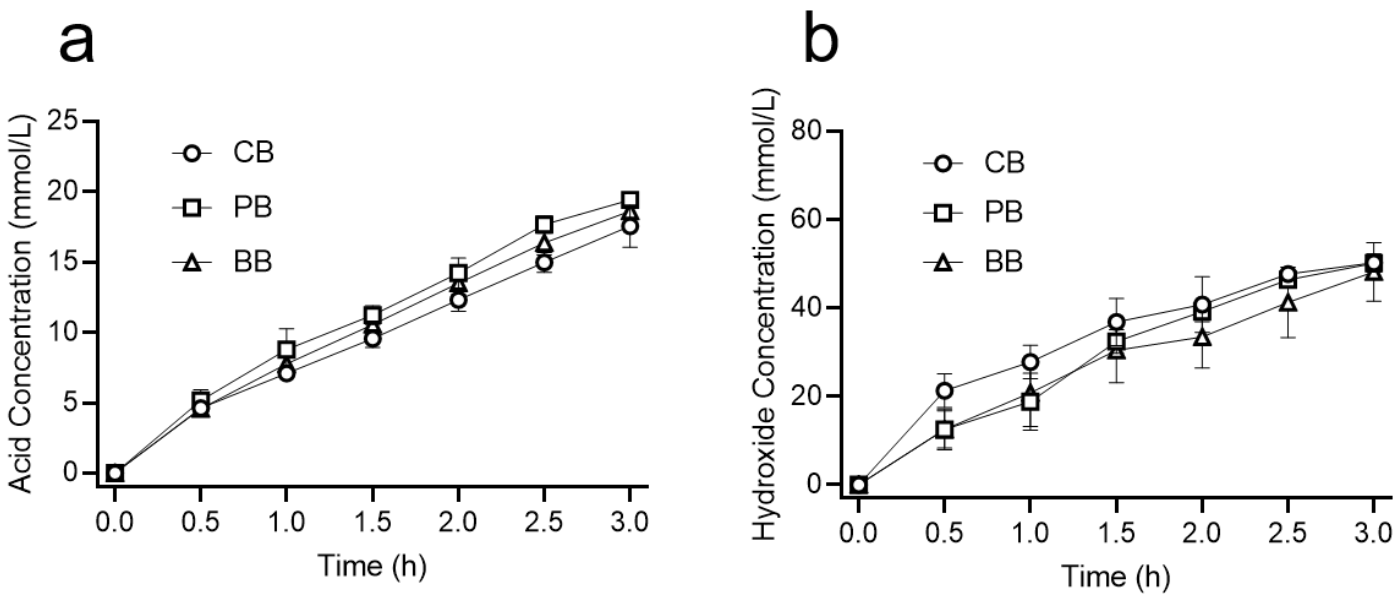

Figure S4. Comparison of different buffers in brine splitting. (a) Acid generation time curves in the anode chamber. (b) Hydroxide generation time curves in the cathode chamber. BB: $0.1 \mathrm{M} \mathrm{H}_{3} \mathrm{BO}_{3} / 0.025 \mathrm{M} \mathrm{Na}_{2} \mathrm{~B}_{4} \mathrm{O}_{7}$ Buffer. PB: 0.1 $\mathrm{M} \mathrm{Na}_{2} \mathrm{HPO}_{4} / 0.1 \mathrm{M} \mathrm{NaH}_{2} \mathrm{PO}_{4}$ Buffer. CB: $0.1 \mathrm{M} \mathrm{Na}_{2} \mathrm{CO}_{3} / 0.1 \mathrm{M} \mathrm{NaHCO}_{3}$ Buffer.

Anode: Ti-Ir. Cathode: stainless steel. Feeding chloride concentration: 11,000 ppm. 

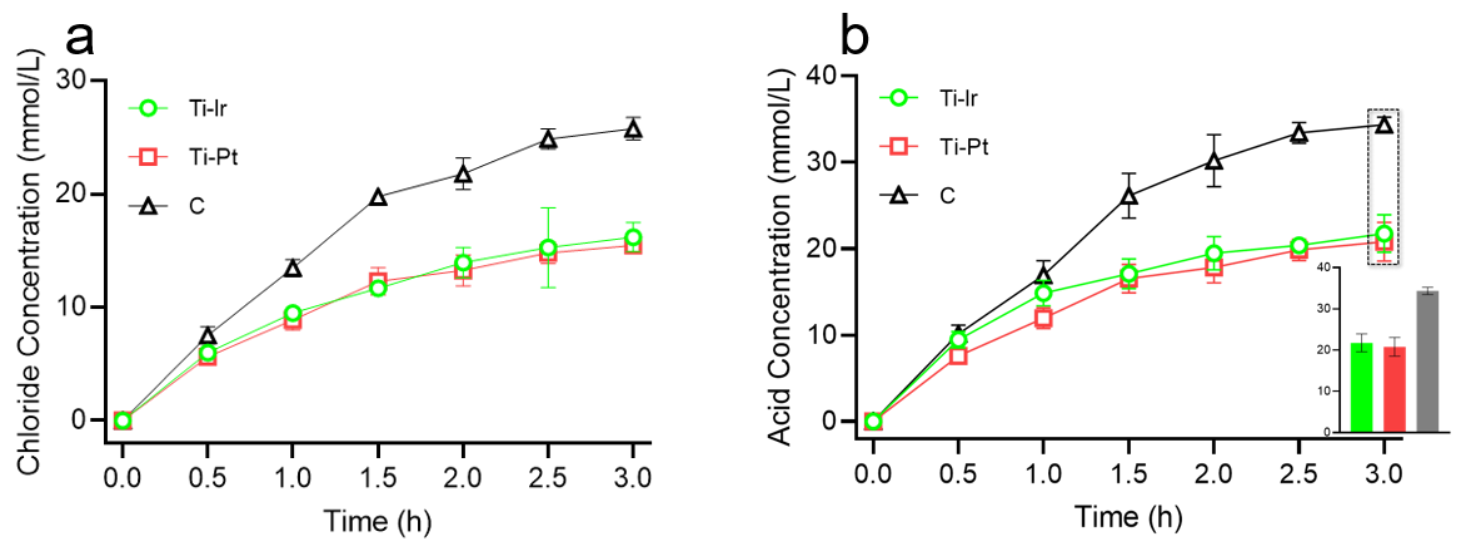

Figure S5. (a) Chloride concentration in anode chamber. (b) Theoretical acid generation time curves calculated by subtracting the chloride lost from the hydroxide generated.
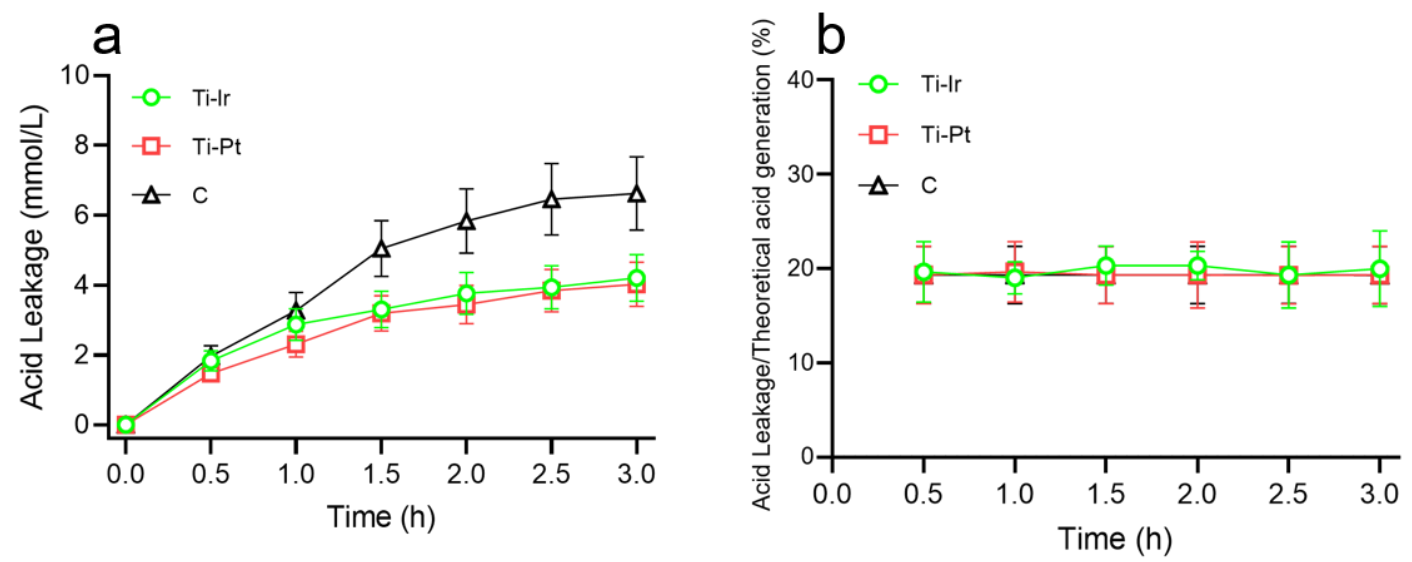

Figure S6. (a) Acid leakage with different anodes, calculated by subtracting the measured proton from the theoretical acid generation. (b) The ratio of acid leakage and theoretical acid generation. 


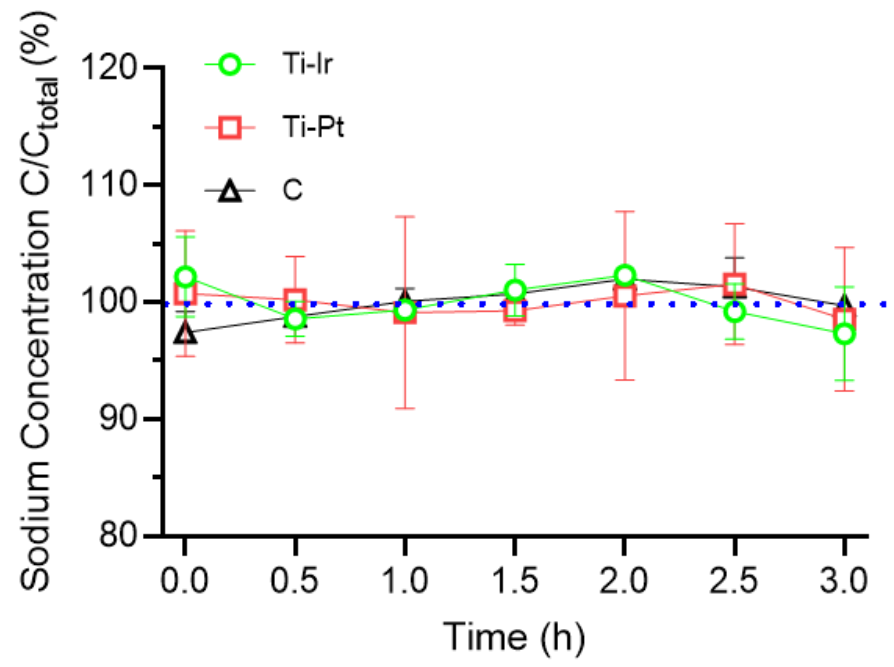

Figure S7. Sodium concentration in the whole system. $\mathrm{C} / \mathrm{C}_{\text {total }}$ : (Sodium concentration at different hours for the whole system)/(Initial sodium concentration of the whole system).

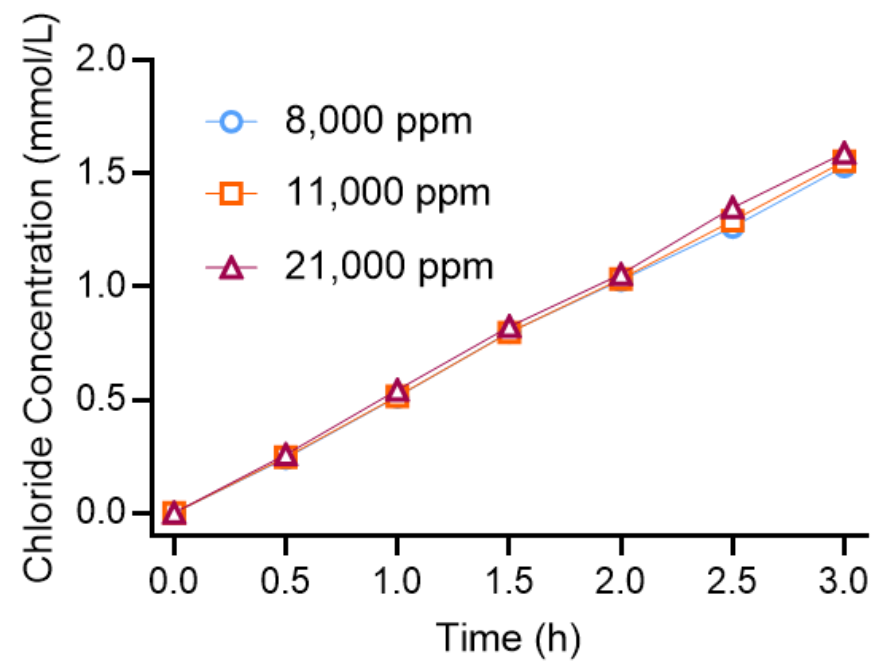

Figure S8. Chloride concentration in anode chamber describing the diffusion through the anion exchange membrane (from feed to anode chamber) in an open circuit system. 


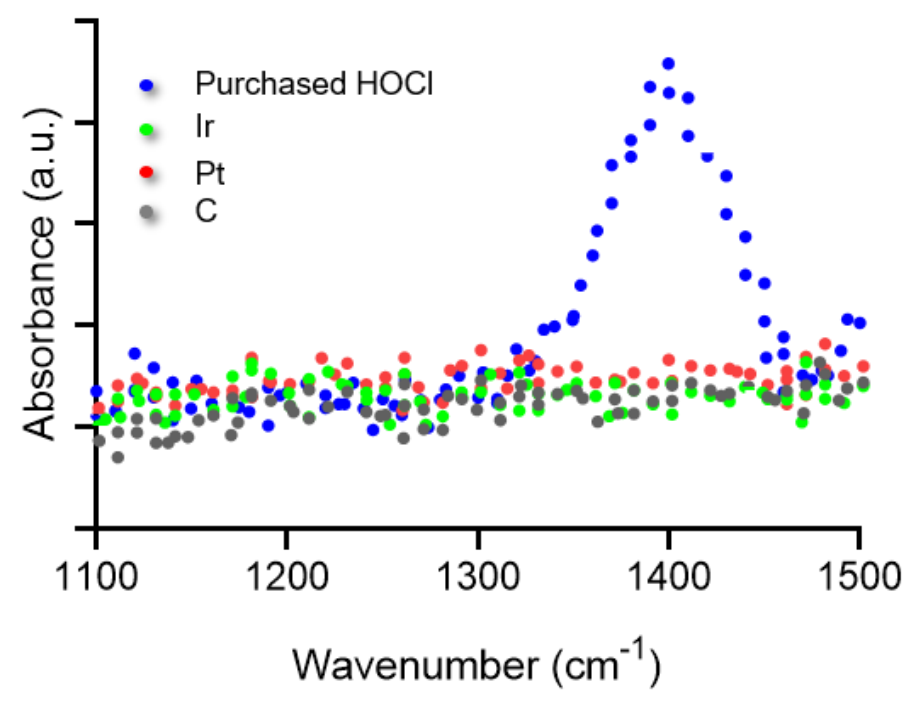

Figure S9. Fourier transform infrared spectroscopy for $\mathrm{Cl}-\mathrm{O}$ bond detection at $1,400 \mathrm{~cm}^{-1}$. The purchased $\mathrm{HOCl}$ is $5 \% \mathrm{w} / \mathrm{v}$ solution. The influent chloride concentration for different anodes is $11,000 \mathrm{ppm}$ and the buffer solution for different anodes is $0.1 \mathrm{M} \mathrm{Na}_{2} \mathrm{CO}_{3} / 0.1 \mathrm{M} \mathrm{NaHCO}_{3}$.

Table S1. Chloride and sodium chloride concentration in synthetic brines tested.

\begin{tabular}{ccc}
\hline $\begin{array}{c}\text { Chloride Concentration } \\
(\mathrm{ppm})\end{array}$ & $\begin{array}{c}\text { Sodium Chloride Concentration } \\
(\mathrm{ppm})\end{array}$ & $\begin{array}{c}\text { Sodium Chloride Concentration } \\
(\mathrm{mmol})\end{array}$ \\
\hline 8,000 & 13,000 & 220 \\
11,000 & 18,000 & 310 \\
21,000 & 35,000 & 600 \\
\hline
\end{tabular}

Table S2. Buffer ion concentrations in synthetic brine and real brine.

\begin{tabular}{ccc}
\hline Buffer Ion & Synthetic Brine & Real Brine \\
\hline $\mathrm{HCO}_{3}{ }^{-} / \mathrm{CO}_{3}{ }^{2-}$ & $100 \mathrm{mM}$ & $34 \mu \mathrm{M}$ \\
$\mathrm{H}_{2} \mathrm{PO}_{4} / \mathrm{HPO}_{4}{ }^{2-}$ & $100 \mathrm{mM}$ & $168 \mu \mathrm{M}$ \\
$\mathrm{H}_{3} \mathrm{BO}_{3} / \mathrm{B}_{4} \mathrm{O}_{7}{ }^{2-}$ & $100 \mathrm{mM}$ & $6 \mathrm{mM}$ \\
\hline
\end{tabular}

